\title{
The Binding Characteristics of Sediment-Derived Dissolved Organic Matter with Ceftazidime: A Microstructural and Spectroscopic Correlation Study
}

\section{Xuewei Cai}

College of Earth and Environmental Science, Lanzhou University

Kemin Qi

College of Earth and Environmental science, Lanzhou University

Xiaoli Zhang

College of Earth and Environmental Science, Lanzhou University

Xiaoyun Xie ( $\nabla$ xiexiaoyun@lzu.edu.cn )

College of Earth and Environmental Science, Lanzhou University

Zhaowei Wang

College of Earth and Environmental Science, Lanzhou University

\section{Research Article}

Keywords: Sediment-derived DOM (SDOM), Cephalosporin antibiotics (CPs), Binding, Microstructural changes, Multi-spectroscopic, Parallel factor analysis (PARAFAC), Two-dimensional correlation spectroscopy (2DCOS).

Posted Date: April 15th, 2021

DOI: https://doi.org/10.21203/rs.3.rs-207173/v1

License: (c) (i) This work is licensed under a Creative Commons Attribution 4.0 International License. Read Full License

Version of Record: A version of this preprint was published at Environmental Science and Pollution Research on January 7th, 2022. See the published version at https://doi.org/10.1007/s11356-021-184310 . 
1 The binding characteristics of sediment-derived dissolved

2 organic matter with ceftazidime: A microstructural and

3 spectroscopic correlation study

5 College of Earth and Environmental Sciences, Lanzhou University, Lanzhou 730000,

6 Key Laboratory for Environmental Pollution Prediction and Control, Gansu Province,

7 China

8

${ }^{*}$ Corresponding author. at: College of Earth and Environmental Sciences, Lanzhou University, Tianshui South Road 222, Lanzhou 730000, Gansu, China.

Tel.: +86 13893448273.

E-mail address:xiexiaoyun@1zu.edu.cn (X. Xie) 


\section{Abstract}

This research focused on the characterization of sediment-derived DOM (SDOM) extracted from sediment of Yellow River and the binding behaviors of ceftazidime (CAZ) with the presence of SDOM. The morphology, surface composition and structure of SDOM and the complexation between SDOM and CAZ in terms of component features, binding capacity and sequence were studied by multiple approaches. Results showed that SDOM was in situ autochthonous-dominated with a low weight-average molecular weight and aromaticity. The multiple morphological characteristics, high surface oxygen contents (53.49\%) and more aliphatic of SDOM were further confirmed. Studies on SDOM-CAZ interaction suggested that the functional groups and chemical compositions of SDOM were susceptible to CAZ. In more detail, the aromatic protons and aliphatic protons of CAZ impacted significantly and the binding between CAZ and SDOM might relate to noncovalent. The protein-like fractions were considered to primary participant and the aromatics and amides as mainly active sites interaction with CAZ. These findings have significant implications on the environmental fate of cephalosporin antibiotics and that of sediment-derived DOM.

\section{Keywords}

Sediment-derived DOM (SDOM); Cephalosporin antibiotics (CPs); Binding; Microstructural changes; Multi-spectroscopic; Parallel factor analysis (PARAFAC); Two-dimensional correlation spectroscopy (2DCOS). 


\section{Introduction}

Cephalosporin antibiotics (CPs), one class of the most universal antibiotic drugs, has been used extensively in human and veterinary treatment (Ribeiro, 2018). Compared with penicillins, as another kind of $\beta$-lactam antibiotics which has comparatively low acid stability and resistance, cephalosporins have less susceptible and allergenic to $\beta$-lactamases and sequentially were accepted as broad spectrum antibiotics (Sader and Jones, 1992; Lin et al., 2000). Once inside the animals or human body, the excess of antibiotics and/or its metabolites may be excreted with urine and feces. Parental cephalosporins and metabolites exist in urine, feces and in other industrial and agricultural residues may enter into soil, surface- and ground waters (Ribeiro, 2018). The properties including chemical and physicochemical of these antibiotics play a significant role for their behavior and fate. (Schwarzenbach et al., 2003). Physical-chemical properties of cephalosporin promote a significant abiotic degradation of these antibiotics, leading to lower residence times of these pharmaceuticals in the environment and lower detections (Junkeretal., 2006). Still and all, the bioactive part of the $\beta$-lactam structure does not change during this transformation (Ribeiro, 2018). As a consequence of the environmental release of these antibiotics, the community structure evolution can be affected (Aminov and Mackie, 2007), which consequently impacts on water ecological function (Kotzerke et al., 2008; Thiele-Bruhn and Beck, 2005). On the other hand, an increasing number of microorganisms resistant to these drugs has been reported in the literature, which would pose hazards to the health of both human and animal (Bouki et al., 2013; Wang and 
Lin, 2014; Walsh, 2000).

The chemical properties that influence and shape the environmental fate of antibiotics are water solubility, hydrophobicity and polarity (Christou et al., 2017). In aquatic environment, water chemical properties such as metal cations and organic ligands would influence the mobility, reactivity, and bioavailability of antibiotics (Benner et al., 1992; Cho et al., 2002; Chen et al., 2016). Dissolved organic matter (DOM) is a complex mixture of aromatic and aliphatic carbon structures with highly heterogeneous molecular properties, and is prevalent in aquatic environment at the milligram degrees of per liter (Graeber et al., 2012; Leenheer and Croue, 2003). Polysaccharides, proteins, and humic substances are most common fractions of DOM (Nebbioso and Piccolo, 2013). These components are regarded as hydrophilic and hydrophobic parts, and they possess the ability to bind hydrophilic / hydrophobic organic pollutants. For instance, due to the colloidal properties of hydrophobic organic pollutants, DOM can increase the solubility of these pollutants in soil and sediment and reduce their adsorption to solid substrates. (Marschner et al., 2005; Chin and Gschwend, 1992). River is the vital migration channel or sinks of organic pollutants by way of runoff and sediments transportation. Compared with the overlying water, most of the contaminants were stored in the sediments (Siev et al., 2018). Therefore, interaction of SDOM with organic contaminants is a vital process need to be reckoned with, and help to understand and analyze the distribution, bioavailability and mobility of organic contaminants in aqueous solution. (Ma and Yates, 2018; Bai et al.,2017). Nevertheless, limited studies about interaction of DOM with antibiotics were reported under 
environmental aquatic conditions.

Several techniques, such as solid phase micro-extraction, dialysis equilibrium, and fluorescence quenching have been used to study the interaction between DOM and organic contaminants (Haftka et al., 2013). Among them, quenching titration combined with three-dimensional excitation-emission matrix (EEM) florescence spectroscopy technique, which enjoys a good reputation in sensitivity, non-destructivity, rapid and easy operation, has proven to be a promising technique to elucidate the complexation of organic contaminants with DOM (Hernandezruiz et al., 2012). Parallel Factor Analysis (PARAFAC), as a decomposition algorithm, is frequently used for decomposing different components in EEMs. ${ }^{1} \mathrm{H}$ Nuclear Magnetic Resonance $\left({ }^{1} \mathrm{H}\right.$ NMR), as a sensitive and effective analytical tool to isomeric discrimination, is dominant to detailedly detect the alterations of noncovalent binding sites between pollutants and organic matter at molecular scale (Longstaffe et al., 2010, Shirzadi et al., 2008). Furthermore, Fourier transform-infrared (FTIR) spectroscopy is a commonly used technique that presents a holistic insight into the chemical bond composition (Ouatmane et al., 2013; Tandy et al., 2010). To further understand the interaction mechanisms of complex compounds, two-dimensional correlation spectroscopy (2DCOS) analysis integrates FTIR spectroscope have been introduced to deconstruct the changes of different functional groups (Chen et al., 2019; Abdulla et al., 2010). 2DCOS was firstly applied to investigate the interaction between sediment-derived DOM and antibiotic contaminants.

As of now, a limited number of literatures about the morphology, composition and 
structure of SDOM were published and the studies about interaction of SDOM and CPs contaminants were almost blank. Aiming to investigate the interaction between SDOM and CPs, ceftazidime (CAZ), the third generation cephalosporin family, which can resistant to hydrolysis by most $\beta$-lactamases has been extensively detected from environmental level about $200 \mathrm{ng} / \mathrm{L}$ to $10 \mathrm{mg} / \mathrm{L}$ in groundwater, secondary effluent and surface water (Ali et al., 2020; Mirzaei et al., 2018; Haller et al., 2018; Yu et al., 2016), was chosen as an agency of CPs in the study. DOM was extracted from aqueous sediment which was collected in Yellow River. UV-Vis spectra, EEM-PARAFAC and FTIR combined with 2DCOS were accepted to investigate the interactions of SDOM fractions with ceftazidime. Furthermore, the changes of interaction sites for noncovalent complexation were evaluated using ${ }^{1} \mathrm{H}$ NMR. The results of our study may help to better explain the properties of sediment-derived DOM and gain an insight of environmental behavior of CPs in aqueous environments.

\section{Materials and methods}

\subsection{Materials prepared}

CAZ was purchased from the Chemical Ltd. (Tokyo) with a purity $>98.0 \%$. Table S1 listed the physicochemical properties of CAZ. Stock solutions of CAZ were all prepared in ultrapure water and cold preserved $\left(4^{\circ} \mathrm{C}\right)$ in the dark surroundings. SDOM was extracted from aqueous sediment with a grab sampler in Yellow River (Lanzhou, China), located in the Zhongshan Bridge region of Gansu province, China. The sediment was collected by the plum blossom sampling method and transported to 
laboratory immediately. Adequate sediment was mixed and freeze-dried, then passed through a $150 \mu \mathrm{m}$ sieve. SDOM was prepared by shaking $\left(250 \mathrm{rpm}, 25^{\circ} \mathrm{C}\right)$ the sediment with ultrapure water for 24 hours, with a sediment-to-water ratio of 1:10 based on sediment dry weight. The suspension was centrifuged (4000 rpm for $30 \mathrm{~min})$ and filtered using glass fiber filters with $0.45 \mu \mathrm{m}$ pore size to acquire the SDOM solution. Some of the solution was stored for later experiments and the remainder was carefully collected and freeze-dried to obtain bulk DOM.

\subsection{Characterization of the SDOM properties}

Total organic carbon (TOC) value of extracted SDOM solution was determined by a TOC analyzer (Elementar vario TOC select). The elements including C, N, S and $\mathrm{H}$ contents of SDOM were determined by elemental analysis (EA). Moreover, SDOM was observed by Field-Emission Scanning Electron Microscope (FE-SEM, JSM-6701F, Japan). Energy dispersive X-ray spectrum (EDS) microanalysis probe (IE250, Oxford Instruments) was used to determine elemental composition of SDOM as well. X-ray photoelectron spectroscopy (XPS) was chose to characterize the chemical composition and structure of original SDOM fractions. Kratos AXIS Ultra DLD spectrometer (Japan) was used to accomplish XPS measure. Spectra analysis was carried out by means of XPSPEAK 4.1 software. The CAZ-SDOM sample was prepared by redissolving bulk SDOM to water with a high concentration of CAZ, and freeze-dried after overnight reaction. Analysis comprised a broad survey scan and a high-resolution scan for major element composition and component speciation, respectively. 


\subsection{Absorbance measurements}

UV-Visible absorption spectra (190-600 nm) of SDOM solution with different concentration of CAZ were obtained at room temperature from UV-Vis spectrophotometer (Evolution 300, Thermo Fisher Scientific).

Equation (1) was used to obtain absorption coefficients:

$$
a_{\lambda}=2.303 \times \mathrm{D}_{\lambda} / \mathrm{r}
$$

where $a_{\lambda}, \mathrm{D}_{\lambda}$, and $\mathrm{r}$ are DOM absorption coefficient at wavelength $\lambda$, corrected optical density at wavelength $\lambda$, and cuvette path length (in $\mathrm{m}$ ), respectively. The optical parameters for the SDOM, including UV absorbance at $254 \mathrm{~nm}\left(\mathrm{UV}_{254}\right)$, the $\mathrm{UV}_{254}$ value of the unit concentration of TOC (SUVA254), E2/ $\mathrm{E}_{3}$ (absorption ratio of $250 \mathrm{~nm}$ to $365 \mathrm{~nm}$ ) and spectral slope ratio $\left(S_{R}\right)$ were calculated respectively and the detail description is given in the Supporting Information.

\section{$2.4{ }^{1} \mathrm{H}$ NMR measurement}

${ }^{1} \mathrm{H}$ NMR spectra were acquired from redissolved freeze-dried SDOM and CAZ at room temperature on a Nuclear magnetic resonance spectrometer (JNM ECS400M). Instrument sensitivity and resolution were $540: 1$ and $0.30 \mathrm{~Hz}(50 \%)$, respectively. $90^{\circ}$ pulse width: $6.25 \mathrm{~ms}$, Magnetic intensity: $9.389 \mathrm{~T}$. The additional parameters to obtain spectra contain: $6000 \mathrm{~Hz}$ spectral width, $5 \mathrm{~s}$ relaxation delay and $2.7 \mu$ s acquisition, 16384 data aggregation points. $\mathrm{D}_{2} \mathrm{O}$ was used to dissolve both $\mathrm{CAZ}$ and SDOM under alkaline condition for the sake of a better solubility. By fixing the mass fraction of CAZ and quantitatively increasing the contents of SDOM, the NMR spectrums were obtained. 
2.5 EEM Fluorescence Spectroscopy and PARAFAC Modeling

EEM spectroscopy as a sensitive, nondestructive and rapid method was recommended to characterize fluorescence of the SDOM. Fluorescence spectra were acquired on a Varian Eclipse spectrofluorometer. Set the voltage of the photomultiplier tube to 750 volts. Excitation wavelengths were set every $5 \mathrm{~nm}$ from 200 to $450 \mathrm{~nm}$ while the emission wavelengths were set from 250 to $700 \mathrm{~nm}$ at $5 \mathrm{~nm}$ intervals. The TOC contents of SDOM were less than $10 \mathrm{mg} \mathrm{C} / \mathrm{L}$ to weaken the inner filtering influences (Wu et al., 2012), and Each fluorescence measurement was subtracted with a Milli-Q water blank.PARAFAC modeling is a well-established method for the characteristic of DOM components that has been introduced in detail previously (Stedmon and Bro, 2008; Bro 1997). In our study, PARAFAC modeling was performed using MATLAB R2017b (MathWorks, Natick, MA) with the DOMFluor Toolbox. The EEMs data array consisted of 40 samples with 91 emission wavelengths and 51 excitation wavelengths. Components and their number were identified and validated by split-half analysis. In order to eliminate the interference of Raman and Rayleigh scattering, EEM of ultrapure water was took out from each EEM of samples and of EEM data close and upper left to the Rayleigh scattering line were all make zero. Then, the visual inspection and residual analysis were proposed to determine the PARAFAC components performed by the toolbox mentioned above. The maximum fluorescence intensities $\left(\mathrm{F}_{\max }\right)$ were used to represent the relative concentrations of the individual fluorescent components. 

were acquired using a spectrofluorometer (Varian Eclipse) equipped with a 150-W xenon excitation source. The excitation wavelengths were $230 \mathrm{~nm}$ and $335 \mathrm{~nm}$, respectively, where $\mathrm{F}_{\max }$ were corresponding highest according to PARAFAC analysis. The emission spectra were recorded from 250 to $550 \mathrm{~nm}$ at $600 \mathrm{~nm} / \mathrm{min}$. A probe thermometer was used to control temperature maintain at $25 \pm 0.5^{\circ} \mathrm{C}$. The measured

where $\mathrm{F}_{0}$ and $\mathrm{F}$ are the fluorescence intensities of SDOM in the absence and presence of CAZ, respectively. $\mathrm{K}$ is the effective binding constant. [CAZ] is the concentration of $\mathrm{CAZ}$, and $\mathrm{n}$ is the binding site number. The Stern-Volmer equation is given as Equation (2):

$$
\frac{F_{0}}{F}=1+K_{S V}[C A Z]
$$

where Ksv is the Sterne-Volmer quenching constant. The thermodynamic functions Equation (3) and (4) were used to study the complexation constants at 288, 298, 308, and $318 \mathrm{~K}$. 


$$
\Delta G^{0}=-R T \ln K^{t}
$$

$$
\ln K^{t}=-\frac{\Delta H^{0}}{R T}+\frac{\Delta S^{0}}{R}
$$

where $K^{t}$ is the binding constant at corresponding temperature $\mathrm{T}$. $\mathrm{R}$ is the ideal gas constant.

2.7 FTIR measurements combined with 2DCOS process

The mixtures of exactly content SDOM sample and different qualities of CAZ were prepared and then dissolved in ultrapure water and freeze-dried after full action. A subsample mixed with $\mathrm{KBr}$ was then compressed twice at nearly 20,000 psi between two polished iron anvils. A degree rotation of $90^{\circ}$ was necessary after the first press to minimize wedging effects to form a $\mathrm{KBr}$ window. A FT-IR Spectrometer (Nicolet Nexus 670, Thermo Fisher Scientific, China) was used to obtain FTIR spectra. In view of the region between 1800 and $900 \mathrm{~cm}^{-1}$ contains the major amides, carboxyl groups, esters, and carbohydrate functional groups, we were just going to focus on this area. The detailed FTIR spectral variations with the addition of CAZ, which was regarded as an external perturbation, were analyzed by the way of 2DCOS. An in-house modified version software named 2Dshige (Shigeaki Morita, Kwansei-Gakuin Ozaki (Noda and Ozaki, 2004). Synchronous map which consists of autopeaks and cross-peaks corresponds a real part of cross function, while asynchronous map which contains only cross-peaks agrees to an imaginary part. Autopeaks along the diagonal line represent the sensitivity of different regions of the system to the change of light intensity under the influence of external disturbance, and cross-peaks located off the 
diagonal line show the sequential order of dynamic spectral variations.

225

226

\section{Results and discussion}

3.1 Absorption spectra analysis

From the absorption spectra of the SDOM, the values for SUVA254, $\mathrm{E}_{2} / \mathrm{E}_{3}, \mathrm{~S}_{275-295}$, $\mathrm{S}_{350-400}$ and $\mathrm{S}_{\mathrm{R}}$ were calculated (Table S2). Compared with the DOM extracted from freshwater, the value of SUVA254 in this study was admittedly lower, indicated autochthonous-dominated DOM origin (Wang et al., 2019). $\mathrm{E}_{2} / \mathrm{E}_{3}$ as a surrogate of the relative molecular weight of humic solutes was calculated to evaluate the relative size of DOM molecules (Helms et al., 2008; Wang et al., 2019). The value of $E_{2} / E_{3}$ for SDOM was higher than the humic substance fractions as reported before (Peuravuori and Pihlaja, 1997; Lou et al., 2006; Du et al., 2018), which indicated its lower average molecular weight. Furthermore, the value of $S_{R}$ was 2.523 manifest the in situ autochthonous origin of SDOM, which is coincident with SUVA254.

\subsection{Analysis of elemental features}

The results for the EA of SDOM are shown in Table S3. Elements carbon (C) and hydrogen $(\mathrm{H})$ are $11.97 \%$ and $1.91 \%$, respectively. More specifically, the SDOM showed a high H/C (1.91), which confirmed that SDOM molecules were more aliphatic (Butturini et al., 2006). Additionally, the nature of SDOM was confirmed by the combination of FE-SEM and EDS, which provided high resolution imaging and elemental composition signatures of SDOM surface structures. FE-SEM revealed the multiple morphological characteristics of SDOM after freeze-dried treatment as 
depicted in Figure 1. Figure 1(a) shows the whole image of SDOM at relative low magnification $(\times 10,000)$. The heterogeneous molecular properties of SDOM were observed and a further exploration was carried with increasing magnification (Figure 1(b) (c)), and more visible size constitute of SDOM was observed. Moreover, Figure 1(d) shows a cylindrical morphology with a cross-sectional diameter more than $0.45 \mu \mathrm{m}$, which could attribute to the shape and the compression of molecule (Wang et al., 2006). The element components of SDOM were determined by EDS (Figure S1). The weight percent of $\mathrm{C}, \mathrm{O}$ and $\mathrm{S}$ is $24.41 \%, 53.49 \%$ and $5.34 \%$, respectively, where manifest a high oxygen content in surface of SDOM.

\section{<Insert Figure 1 here>}

XPS measurements can provide the changes of valuable and important electronic structure information of SDOM before and after interactions with CAZ, and facilitate us gain an insight into the interaction between SDOM and organic pollutants. A further study of the interactions between the SDOM and CAZ using XPS spectroscopy was carried out (Figure 2). Figure 2(a) showed the full XPS spectra of samples in the energy range of $0-800 \mathrm{eV}$, where the main peaks corresponding to the $\mathrm{C} 1 \mathrm{~s}$ and $\mathrm{O} 1 \mathrm{~s}$ were located at binding energies of $284.6 \mathrm{eV}$ and $531 \mathrm{eV}$, respectively (Zhao et al., 2017). In order to acquire more detailed chemical bonds information of elements including $\mathrm{C}$ $(284.6 \mathrm{eV}), \mathrm{N}(399.2 \mathrm{eV})$ and $\mathrm{O}(531.2 \mathrm{eV})$, the high-resolution scans were proposed before and after CAZ bonding with SDOM (Figure 2(b), (c) and (d)). The characteristic peaks of $\mathrm{O}$ and $\mathrm{C}$ 1s in both SDOM and SDOM-CAZ system corresponded to aliphatic $\mathrm{C}-\mathrm{C}$ bonds $(284.6 \mathrm{eV})$, phenolic, alcoholic, or etheric $\mathrm{C}-(\mathrm{O}, \mathrm{N})$ bonds $(286.0 \mathrm{eV})$, 
carboxylic $\mathrm{O}=\mathrm{C}-\mathrm{O}$ group $(288.8 \mathrm{eV})$, carboxylate, carbonyl, ester or amide $\mathrm{O}=\mathrm{C}$ group (531.2 eV) and alcohols, hemiacetal, or acetal groups C-O group (532.3 eV) (Du et al., 2018; Zhou et al., 2017). The N1s XPS spectra of SDOM exhibited two peaks under high resolution: binding energy at $399.2 \mathrm{eV}$ perceived as the nonprotonated nitrogen atoms $\left(\mathrm{N}_{\text {nonpr }}\right)$ in the forms of amine or amide and binding energy at $400.8 \mathrm{eV}$ and 402.8 $\mathrm{eV}$ perceived as the protonated nitrogen $\left(\mathrm{N}_{\mathrm{pr}}\right)$ (Templier et al., 2012; Zhou et al., 2017). These results indicated that the DOM derived from sediment were rich in lipids, proteins and saccharides.

\section{<Insert Figure 2 here $>$}

Significant increase in the intensity of C $1 \mathrm{~s}$ at $288.8 \mathrm{eV}$ was observed in the SDOM-CAZ sample, which could be more than two line shapes with intensity in SDOM. As well as, the intensity of C $1 \mathrm{~s}$ at $284.6 \mathrm{eV}$ decreased in SDOM-CAZ system compared with CAZ absent. A shift of approximately $0.2 \mathrm{eV}$ of the three $\mathrm{C} 1 \mathrm{~s}$ peaks was occurred in the SDOM-CAZ system, most likely result from the complexation of SDOM with CAZ. The loss of organic oxygen in the SDOM, may be attributed to the generation of $\mathrm{H}_{2} \mathrm{O}$ and $\mathrm{CO}_{2}$ (Wang et al., 2014a), was observed after the interaction with CAZ. In addition, consistent with the NOM extracted from a river, $\mathrm{N}_{\text {nonpr }}$ was the main form of $\mathrm{N}$ element compared with $\mathrm{N}_{\mathrm{pr}}$ for SDOM (Meng et al., 2012). It is interesting to note that the addition of CAZ caused considerable increase in the abundance of both $\mathrm{N}_{\text {nonpr }}$ and $\mathrm{N}_{\mathrm{pr}}$, and the increases of $\mathrm{N}_{\mathrm{pr}}$ is even more. Briefly, the functional groups and chemical compositions (i.e., aromatics, proteins-like structures) of DOM derived from sediment were susceptible to CAZ. 
${ }^{1} \mathrm{H}$ NMR spectroscopy of selected ceftazidime were indicative of substantial variance and detailed structural information according to concentration ratios of CAZ to SDOM (Figure 3). The SDOM samples containing different level of CAZ showed clear-cut envelopes from ${ }^{1} \mathrm{H}$ NMR spectra, which indicated the intrinsic averaging from massive signal overlap (Cortés-Francisco et al., 2014). A detailed description of key structural units of prepared CAZ and SDOM-CAZ systems was presented in supporting methyl group $\left(\delta_{\mathrm{H}} \sim 1.38 \mathrm{ppm}\right)$ and were drew from $\delta_{\mathrm{H}} \sim 1.2-8.9 \mathrm{ppm}$ (excluding deuteroxide) as shown in Figure 3. The fundamental substructures was showed from higher to lower field (from right to left): pure aliphatic $\delta_{\mathrm{H}} \sim 1.2-2.0 \mathrm{ppm}, \mathrm{H}_{3}-\mathrm{C}-\mathrm{C}$; monosubstituted and disubstituted alkanes $\delta_{\mathrm{H}} \sim 2.0-6.0 \mathrm{ppm}, \mathrm{CH}_{2}-$; olefins $\delta_{\mathrm{H}} \sim 6.0-7.6$ ppm, $\mathrm{HC}=\mathrm{C}$ and aromatic $\delta_{\mathrm{H}} \sim 7.6-8.9 \mathrm{ppm}, \mathrm{H}_{\mathrm{ar}} \mathrm{NMR}$ resonances (Dvorski et al., 2016).

\section{<Insert Figure 3 here>}

Significant changes of ${ }^{1} \mathrm{H}$ NMR spectroscopy were observed with the addition of SDOM. These spectrums firstly manifested variable contributions of selected CAZ, that showed sharp NMR resonances with well resolved splitting peaks from J-couplings. Three different concentration ratios $(9.0: 1,5.4: 1$ and $1.8: 1$, respectively) of CAZ to SDOM were prepared to analyze. Note that in ratio of 9.0:1, CAZ still exhibits distinct splitting peaks and highly relative intensity. With the increase of SDOM concentration, the shape of ${ }^{1} \mathrm{H}$ NMR spectra for CAZ were broadened and the proton signals gradually weak, meanwhile the peaks associated with spin-spin coupling melted into one peak 

and $6.85 \mathrm{ppm}$ weakened more visualized upon addition of SDOM even at one ninth of the CAZ concentration, which also means that branched methyl groups and amino attached to heterocycles were noticeably affected by SDOM even at a low concentration (Dvorski et al., 2016). Furthermore, with a close-up view of expanded difference spectrum (Figure 3, inset), a slight chemical shift in the peaks of both aromatic protons

(e.g. j, n) and aliphatic protons (e.g. f) was observed. It is clearly showed that protons become sostenuto quenched with the increasing of SDOM concentration, and the splitting peaks lost gradually with the broaden of upfield peaks. Peaks broadening can be the result of faster relaxation of the excited nuclei, and the reason of more rapid relaxation may be attribution to a convenient path provided by the interaction of the CAZ with SDOM (Bedard et al., 2014). Results including peak broadening and quenching coupled with changing of chemical shifts in NMR peak positions might relate to noncovalent binding between CAZ and SDOM (Nanny et al., 2001).

\subsection{Fluorescence properties of SDOM-CAZ complexations}

The raw EEM spectra of the isolated SDOM and the SDOMs with the addition of CAZ (0-27 mg/L, concentration interval: $3 \mathrm{mg} / \mathrm{L})$ are depicted in Figure $\mathrm{S} 2$. In the absence of CAZ (Figure S2a), the EEM spectrum of SDOM showed two peaks, which were identified as protein-like and humic-like substances, respectively (Chen et al., 2003; Wu et al., 2011; Fu et al., 2016). The impact of CAZ on the conformation of DOM was researched by fluorescence emission spectra (Figure S3), and the microenvironment of fluorescent functional regions was analyzed detailedly in 
Supporting Information as well. CAZ nearly one-side fluorescence quenching with protein-like components of SDOM was ascribed to the changes of electronic structure in protein-like substances when forming SDOM-CAZ complexes. Compared with emission spectra at $E x=335 \mathrm{~nm}$, the quenching effect of $C A Z$ at $E x=230 \mathrm{~nm}$ was greater, which indicated that the intrinsic fluorescence quenching of SDOM was mainly happened at low excitation wavelength. Furthermore, low contents would also be one reason for the limited contribution of humic-like fraction $(E x=335 \mathrm{~nm})$ in the interaction with CAZ. In consequence, these results make receivable sense that the affinity of the CAZ binding with the SDOM was differ significantly in SDOM fractions. The thermodynamic characteristics of SDOM-CAZ system were evaluated quantifiably (Table S5), and the results indicated that an optimum temperature was nearly $35{ }^{\circ} \mathrm{C}$ in the binding between SDOM components and CAZ. Linear relationships were observed for SDOM with CAZ. According to the $\mathrm{n}$ values, there are more than one class of binding sites in both tryptophan-like and fulvic acid-like component for CAZ.

The binding characteristics of individual SDOM components with CAZ were evaluated by the means of EEM-PARAFAC analysis, and four different components (C1-4) were isolated according to the EEMs acquired from the addition of CAZ (Figure 4, Figure S4). $\mathrm{C} 1$ and $\mathrm{C} 3$ are located at humic-like fluorescence region, while $\mathrm{C} 2$ was regarded as tryptophan-like fraction. C4, with the Ex/Em ranges of $<200-230 / 280-550$ $\mathrm{nm}$, covers the EEM spectral regions of both humic-like and tryptophan-like fluorescence (Coble, 1996). In SDOM, C2 has a significant quenching even though at a relatively low CAZ concentration. As the increasing of CAZ concentration $(0-27 \mathrm{mg}$ 
/ L), the $\mathrm{F}_{\max }$ value of $\mathrm{C} 2$ continues to decrease while the fluorescence quenching effects of $\mathrm{C} 1$ and $\mathrm{C} 3$ are weak during the entire process. The fluorescence of $\mathrm{C} 4$ shows a downward trend as well, but the content of $\mathrm{C} 4$ is less enough to negligible. When the concentration of CAZ increased to the maximum value $(27 \mathrm{mg} / \mathrm{L})$, the detectable fractions of $\mathrm{C} 1, \mathrm{C} 2$ and $\mathrm{C} 3$ are $86 \%, 51 \%$ and $88 \%$, respectively. Similar result that the quenching of tryptophan fractions was more significant compared with humic-like fractions has been reported before (Baker, 2005). Hence, we can deduce that the binding properties of SDOM were highly correlated with its individual components and the protein-like components in SDOM have a high affinity with CAZ.

\section{<Insert Figure 4 here>}

\subsection{FTIR Analysis combined with 2D Correlation Spectroscopy}

The FTIR spectra of free CAZ, free SDOM and SDOM-CAZ mixture are illustrated in Figure S5. Free SDOM and SDOM-CAZ mixture showed a similar shape with broad and complex contours, shown in the same vertical coordinate. The details of the peaks in the FTIR have been described. The broad band around $3430 \mathrm{~cm}^{-1}$ corresponded to the H-bonded $\mathrm{OH}$ groups of carboxylic and phenols, as a supplement, the N-H stretching of amines and amides possibly make a contribution as well (Ouatmane et al., 2013; Bai et al., 2017). The well pronounced broad peak around 1630 $\mathrm{cm}^{-1}$ was attributable to the aromatic $\mathrm{C}=\mathrm{C}, \mathrm{C}=\mathrm{O}$ and / or amide $\mathrm{I} \mathrm{C}=\mathrm{O}$ stretch (Bosch Reig et al., 2002; Tandy et al., 2010), while the peak around $1460 \mathrm{~cm}^{-1}$ was identified as the $\mathrm{N}=\mathrm{O}$ stretching of aromatic groups (Abdulla et al., 2010). Peaks at the 1280 to $1200 \mathrm{~cm}^{-1}$ range were due to the vibration of C-O and O-H in amide III associated with 
COOH groups (Smith, 1999; Tandy et al., 2010). Some peaks of SDOM changed via binding with CAZ. The peaks at 1640 and $1230 \mathrm{~cm}^{-1}$ all fortified, and the intensity of the peak around $1460 \mathrm{~cm}^{-1}$ judged as the $\mathrm{N}=\mathrm{O}$ stretching of aromatic groups was significantly reduced. Conclusion above, the bands of $\mathrm{C}=\mathrm{C}, \mathrm{C}=\mathrm{O}, \mathrm{N}=\mathrm{O}, \mathrm{O}-\mathrm{H}$ and $\mathrm{C}-\mathrm{O}$ in SDOM were all involved in the binding of CAZ, which indicated that the aromatics, amide I and III in SDOM were the main constituents responsible for the interaction with CAZ.

\section{<Insert Figure 5 here $>$}

To probe the structural variation in the interaction between SDOM and CAZ, 2DCOS analyses were performed using the FTIR spectra (Figure 5). The concentration of the CAZ was used as an external variable. In the synchronous map (Figure 5(a)), major autopeaks were captured at 1464,1232 , and $1090 \mathrm{~cm}^{-1}$. The autopeak centred at $1464 \mathrm{~cm}^{-1}$ has the highest chroma, followed by the peaks at 1090 and $1232 \mathrm{~cm}^{-1}$, manifested that the different sensitivity of three regions to the influence of external disturbance. The band at $1464 \mathrm{~cm}^{-1}$ was associated with $\mathrm{N}=\mathrm{O}$ stretching of aromatic groups, and the band at $1232 \mathrm{~cm}^{-1}, 1090 \mathrm{~cm}^{-1}$ was assigned to the $\mathrm{C}-\mathrm{O}$ stretching of carboxyl and of polysaccharides or polysaccharide-like substances, respectively (Tandy et al., 2010; Yu et al., 2011; Hu et al., 2008). Furthermore, three positively correlated crosspeaks at $\left(1464 \mathrm{~cm}^{-1}, 1232 \mathrm{~cm}^{-1}\right),\left(1464 \mathrm{~cm}^{-1}, 1090 \mathrm{~cm}^{-1}\right)$, and $\left(1232 \mathrm{~cm}^{-1}, 1090\right.$ $\mathrm{cm}^{-1}$ ) were identified, suggesting that $\mathrm{N}=\mathrm{O}$ stretching of aromatic groups, $\mathrm{C}-\mathrm{O}$ of saccharides, and $\mathrm{C}-\mathrm{O}$ of carboxyl varied/degraded concurrently during complexing. The asynchronous map depicted distinctive characteristics (Figure 5(b)) compared to 
the synchronous map. In the asynchronous maps, three positive crosspeaks at $\left(1465 \mathrm{~cm}^{-}\right.$ 1, $\left.1241 \mathrm{~cm}^{-1}\right),\left(1467 \mathrm{~cm}^{-1}, 1122 \mathrm{~cm}^{-1}\right)$, and $\left(1467 \mathrm{~cm}^{-1}, 1027 \mathrm{~cm}^{-1}\right)$ and five negative crosspeaks at $\left(1770 \mathrm{~cm}^{-1}, 1650 \mathrm{~cm}^{-1}\right),\left(1650 \mathrm{~cm}^{-1}, 1465 \mathrm{~cm}^{-1}\right),\left(1633 \mathrm{~cm}^{-1}, 1232 \mathrm{~cm}^{-1}\right)$, $\left(1650 \mathrm{~cm}^{-1}, 1091 \mathrm{~cm}^{-1}\right)$, and $\left(1243 \mathrm{~cm}^{-1}, 1089 \mathrm{~cm}^{-1}\right)$ were observed. On the basis of Noda's rule, the sequential order of FTIR dynamic spectral variations was inferred as follows: $1464 \mathrm{~cm}^{-1}>1090 \mathrm{~cm}^{-1}>1232 \mathrm{~cm}^{-1}$. Correspondingly, as illustrated in Figure 5(c), organic compounds were changed in the following sequence: $\mathrm{N}=\mathrm{O}$ stretching of aromatic groups $>$ C-O of polysaccharides $>$ C-O of carboxyl.

\section{Conclusions}

This study investigated the binding properties of sediment-derived DOM with CAZ as an agency of CPs contaminants by multiple techniques for the first time. The morphological characteristics of SDOM were heterogeneous, and a high surface oxygen content was checked out. Though two main fluorescent components are determined in SDOM, compared with humic-like substances, the protein-like components have more obvious affinity with CAZ. The aliphatics and amides may as mainly active sites in protein-like fluorophores interaction with CAZ. The aromatics, amide I and III in SDOM may as mainly active sites for the interaction with CAZ. Structural features of SDOM before and after CAZ presence exhibited a noticeable change, and the bands of $\mathrm{C}=\mathrm{C}, \mathrm{C}=\mathrm{O}, \mathrm{N}=\mathrm{O}, \mathrm{O}-\mathrm{H}$ and $\mathrm{C}-\mathrm{O}$ in SDOM were all involved in the binding of CAZ, which proved that the structure characteristics of SDOM is evidently influenced by CAZ. In summary, SDOM has a major impact on the fate and transport of CAZ in aqueous environment. DOM in aqueous environment plays the 
non-negligible role in the fate and transport of environmentally concerned chemicals. Interactions of sediment-derived DOM with antibiotics is of crucial to the transport, transformation and ecotoxicity of antibiotics in aqueous environment. Our study gives a deeper insight on the role of SDOM in aqueous environment and improves the knowledge basis to better assess the ecological risk of CPs.

\section{Ethics approval and consent to participate}

Not applicable.

\section{Consent for publication}

429 Not applicable.

\section{$430 \quad$ Availability of data and materials}

431 All the data and tools/models used for this work are publicly available.

\section{Competing interests}

433 The authors declare that they have no conflict of interest.

\section{$434 \quad$ Funding}

435 This work was supported by the National Natural Science Foundation of China (Grant:

$436 \quad 42077330)$.

\section{Authors' contributions}

All authors contributed to the study conception and design. Material preparation, data collection and analysis were performed by Xuewei Cai, Kemin Qi, Xiaoli Zhang,

440 Xiaoyun Xie and Zhaowei Wang.The first draft of the manuscript was written by Xuewei Cai and all authors commented on previous versions of the manuscript. All 
442 authors read and approved the final manuscript.

443 


\section{References}

Abdulla HAN, Minor EC, Hatcher PG (2010) Using Two-dimensional correlations of ${ }^{13} \mathrm{C}$ NMR and FTIR to investigate changes in the chemical composition of dissolved organic matter along an estuarine transect. Environ Sci Technol 44: 8044-8049

Alexandrino DAM, Mucha AP, Almeida MR, Gao W, Jia Z, Carvalho MF (2017) Biodegradation of the veterinary antibiotics enrofloxacin and ceftiofur and associated microbial community dynamics. Sci Total Environ 581-582: 359-368

Ali MS, Muthukumaran J, Al-Lohedan H (2020) Molecular interactions of ceftazidime with bovine serum albumin: Spectroscopic, molecular docking, and DFT analyses. J Mol Liq 313: 113490

Aminov RI, Mackie RI (2007) Evolution and ecology of antibiotic resistance genes. Fems Microbiol Lett 271: 147-161

Bai LL, Cao CC, Wang CL, Wang CH, Zhang H, Jiang HL (2017) Roles of phytoplankton- and macrophyte-derived dissolved organic matter in sulfamethazine adsorption on goethite. Environ Pollut 230: 87-95

Bai LL, Zhao Z, Wang CL, Wang CH, Liu X, Jiang HL (2017) Multi-spectroscopic investigation on the complexation of tetracycline with dissolved organic matter derived from algae and macrophyte. Chemosphere 187: 421-429

Baker A (2005) Thermal fluorescence quenching properties of dissolved organic matter. Water Res 39: 4405-4412

Bedard M, Giffear KA, Ponton L, Sienerth KD, Moore VDG (2014) Characterization 
of binding between $17 \beta$-estradiol and estriol with humic acid via NMR and biochemical analysis. Biophys Chem 189: 1-7

Benner R, Pakulski JD, Mccarthy M, Hedges JI, Hatcher PG (1992) Bulk chemical characteristics of dissolved organic matter in the ocean. Science 255: 1561-1564

Bosch Reig F, GiGimeno Adelantado JV, Moya Morena MCM (2002) FTIR quantitative analysis of calcium carbonate (calcite) and silica (quartz) mixtures using the constant ratio method. Application to geological samples. Talanta 58: 811-821

Bouki C, Venieri D, Diamadopoulos E (2013) Detection and fate of antibiotic resistant bacteria in waste water treatment plants: a review. Ecotoxicol Environ Saf 91: 1-9

Bro R (1997) PARAFAC. Tutorial and applications. Chemometrics and Intelligent Laboratory Systems 38: 149-171

Butturini A, Herzsprung p, Lechtenfeld OJ, Venturi S, Amalfitano S, Vazquez E, Pacini N, Harper DM, Tassi F, Fazi S (2020) Dissolved organic matter in a tropical salinealkaline lake of the East African Rift Valley. Water Res 173: 115532

Chen JB, Sun PZ, Zhang YL, Huang CH (2016) Multiple roles of Cu(II) in catalyzing hydrolysis and oxidation of $\beta$-lactam antibiotics. Environ Sci Technol 50, 1215612165

Chen W, Teng CY, Qian C, Yu HQ (2019) Characterizing properties and environmental behaviors of dissolved organic matter using two-dimensional correlation spectroscopic analysis. Environ Sci Technol 53: 4683-4694

Chen W, Westerhoff P, Leenheer JA, Booksh K (2003) Fluorescence excitation- 
emission matrix regional integration to quantify spectra for dissolved organic matter. Environ Sci Technol 37: 5701-5710

Chen ZY, Zhang YJ, Gao YZ, Boyd SA, Zhu DQ, Li H (2015) Influence of dissolved organic matter on tetracycline bioavailability to an antibiotic-resistant bacterium. Environ Sci Technol 49: 10903-10910

Cho HH, Park JW, Liu CCK (2002) Effect of molecular structures on the solubility enhancement of hydrophobic organic compounds by environmental amphiphiles. Environ Toxicol Chem 21: 999-1003

Christou A, Agüera A, Bayona JM, Cytryn E, Fotopoulos V, Lambropoulou D, Manaia CM, Michael C, Revitt M, Schröder P, Fatta-Kassinos D (2017) The potential implications of reclaimed wastewater reuse for irrigation on the agricultural environment: The knowns and unknowns of the fate of antibiotics and antibiotic resistant bacteria and resistance genes - A review. Water Res 123: 448-467

Coble PG (1996) Characterization of marine and terrestrial DOM in seawater using excitation-emission matrix spectroscopy. Mar Chem 51 (4): 325-346

Cortés-Francisco N, Harir M, Lucio M, Ribera G, Martínez-Lladó X, Rovira M, Schmitt-Kopplin P, Hertkorn N, Caixach J (2014) High-field FT-ICR mass spectrometry and NMR spectroscopy to characterize DOM removal through a nanofiltration pilot plant. Water Res 67: 154-165

Du Y, Wu QY, Lv XT, Ye B, Zhan XM, Lu Y, Hu HY (2018) Electron donating capacity reduction of dissolved organic matter by solar irradiation reduces the cytotoxicity formation potential during wastewater chlorination. Water Res 145: 94-102 
Du ZY, He YS, Fan JN, Fu HY, Zheng SR, Xu ZY, Qu XL, Kong A, Zhu DQ (2018) Predicting apparent singlet oxygen quantum yields of dissolved black carbon and humic substances using spectroscopic indices. Chemosphere 194: 405-413

Dvorski SE, Gonsior M, Hertkorn N, Uhl J, Müller H, Griebler C, Schmitt-Kopplin P (2016) Geochemistry of dissolved organic matter in a spatially highly resolved groundwater petroleum hydrocarbon plume cross-section. Environ Sci Technol 50: $5536-5546$

Ferrie RP, Hewitt GE, Anderson B (2017) EXPRESS: a fluorescence quenching analysis of the binding of fluoroquinolones to humic acid. Appl Spectrose 71: $2512-2518$

Fu QL, He JZ, Blaney L, Zhou DM (2016) Roxarsone binding to soil-derived dissolved organic matter: Insights from multi-spectroscopic techniques. Chemosphere 155: $225-233$

Gauthier TD, Shane EC, Guerin WF, Rudolf Seitz W, Grant CL (1986) Fluorescence quenching method for determining equilibrium constants for polycyclic aromatic hydrocarbons binding to dissolved humic materials. Environ Sci Technol 20: $1162-1166$

Graeber D, Gelbrecht J, Pusch MT, Anlanger C, von Schiller D (2012) Agriculture has changed the amount and composition of dissolved organic matter in Central European headwater streams. Sci Total Environ 438: 435-446

Haftka JJH, Scherpenisse P, Jonker MTO, Hermens JLM (2013) Using polyacrylatecoated SPME fibers to quantify sorption of polar and ionic organic contaminants 
Helms JR, Stubbins A, Ritchie JD, Minor EC, Kieber DJ, Mopper K (2008) Absorption spectral slopes and slope ratios as indicators of molecular weight, source, and photobleaching of chromophoric dissolved organic matter. Limnol Oceanogr 53: 955-969

Hernandez-Ruiz S, Abrell L, Wickramasekara S, Chefetz B, Chorover J (2012) Quantifying PPCP interaction with dissolved organic matter in aqueous solution: Combined use of fluorescence quenching and tandem mass spectrometry. Water Res 46: 943-954

Hertkorn N, Benner R, Witt m, Frommberger M, Schmitt-Kopplin p, Kaiser K, Kettrup A, Hedges IJ (2007) An integrated NMR and FTCIR mass spectroscopic study to characterize a new and major refractory component of (marine) natural organic matter (NOM) at the molecular level, CRAM: Carboxyl-rich alicyclic molecules. Geochim Cosmochim Acta 71: A399-A399

Hu ZH, Liu SY, Yue ZB, Yan LF, Yang MT, Yu HQ (2008) Microscale analysis of in vitro anaerobic degradation of lignocellulosic wastes by rumen microorganisms. Environ Sci Technol 42: 276-281

Junker T, Alexy R, Knacker T, Kümmerer K (2006) Biodegradability of ${ }^{14} \mathrm{C}$-labeled antibiotics in a modified laboratory scale sewage treatment plant at environmentally relevant concentrations. Environ Sci Technol 40: 318-324

Kotzerke A, Sharma S, Schauss K, Heuer H, Thiele-Bruhn S, Smalla K, Wilke BM, Schloter M (2008) Alterations in soil microbial activity and N-transformation 
Leenheer JA, Croue JP (2003) Characterizing aquatic dissolved organic matter. Environ Sci Technol 37: 18A-26A

Li B, Zhang T (2010) Biodegradation and adsorption of antibiotics in the activated sludge process. Environ Sci Technol 44: 3468-3473

Lin CE, Chen HW, Lin EC, Lin KS, Huang HC (2000) Optimization of separation and migration behavior of cephalosporins in capillary zone electrophoresis. J Chromatogr A 879: 197-210

Longstaffe JG, Simpson MJ, Maas W, Simpson AJ (2010) Identifying components in dissolved humic acid that bind organofluorine contaminants using ${ }^{1} \mathrm{H}\left\{{ }^{19} \mathrm{~F}\right\}$ reverse heteronuclear saturation transfer difference NMR spectroscopy. Environ Sci Technol 44: 5476-5482

Lou T, Xie HX (2006) Photochemical alteration of the molecular weight of dissolved organic matter. Chemosphere 65: 2333-2342

Ma L, Yates SR (2018) Dissolved organic matter and estrogen interactions regulate estrogen removal in the aqueous environment: A review. Sci Total Environ 640641: $529-542$

Marschner B, Winkler R, Jodemann D (2004) Factors controlling the partitioning of pyrene to dissolved organic matter extracted from different soils. Eur J Soil Sci 56: 299-306

Meng FG, Huang GC, Li ZQ, Li SY (2012) Microbial transformation of structural and functional makeup of human-impacted riverine dissolved organic matter. Ind Eng 
Nanny MA, Maza JP (2001) Noncovalent interactions between monoaromatic compounds and dissolved humic acids: a deuterium NMR T1 relaxation study. Environ Sci Technol 35: 379-384

Noda I, Ozaki Y (2004) Two-Dimensional Correlation Spectroscopy - Applications in Vibrational and Optical Spectroscopy. John Wiley \& Sons Ltd: London.

Nebbioso A, Piccolo A (2013) Molecular characterization of dissolved organic matter (DOM): a critical review. Anal. Bioanal. Chem 405: 109-124

Ouatmane A, Provenzano MR, Hafidi M, Senesi N (2013) Compost Maturity Assessment Using Calorimetry, Spectroscopy and Chemical Analysis. Compost Sci Util 8: 124-134

Pan B, Qiu MY, Wu M, Zhang D, Peng HB, Wu D, Xing BS (2012) The opposite impacts of $\mathrm{Cu}$ and $\mathrm{Mg}$ cations on dissolved organic matter-ofloxacin interaction. Environ Pollut 161: 76-82

Peuravuori J, Pihlaja K (1997) Molecular size distribution and spectroscopic properties of aquatic humic substances. Anal Chim Acta 337: 133-149

Ribeiro AR, Sures B, Schmidt TC (2018) Cephalosporin antibiotics in the aquatic environment: A critical review of occurrence, fate, ecotoxicity and removal technologies. Environ Pollut 241: 1153-1166

Sader HS, Jones RN (1992) Historical overview of the cephalosporin spectrum: four generations of structural evolution. Antimicrobic Newsletter 8: 75-84

Schwarzenbach RB, Gschwend PM, Imdoben DM (2003) Environmental Organic 
Shirzadi A, Simpson MJ, Xu Y, Simpson AJ (2008) Application of saturation transfer

Siev S, Yang H, Sok T, Uk S, Song L, Kodikara D, Oeurng C, Hul S, Yoshimura C double difference NMR to elucidate the mechanistic interactions of pesticides with humic acid. Environ Sci Technol 42: 1084-1090 (2018) Sediment dynamics in a large shallow lake characterized by seasonal flood pulse in Southeast Asia. Sci Total Environ 631-632: 597-607

Smith B (1999) Infrared Spectral Interpretation. CRC Press, London

Stedmon CA, Bro R (2008) Characterizing dissolved organic matter fluorescence with parallel factor analysis: a tutorial. Limnol Oceanogr-Meth 6: 572-579

Tandy S, Healey JR, Nason MA, Williamson JC, Jones DL, Thain SC (2010) FT-IR as an alternative method for measuring chemical properties during composting. Bioresource Technol 101: 5431-5436

Templier J, Miserque F, Barré N, Mercier F, Croué JP, Derenne S (2012) Is nitrogen functionality responsible for contrasted responses of riverine dissolved organic matter in pyrolysis? J Anal Appl Pyrolysis 97: 62-72

Thiele-Bruhn S, Beck IC (2005) Effects of sulfonamide and tetracycline antibiotics on soil microbial activity and microbial biomass. Chemosphere 59: 457-465

Walsh C (2000) Molecular mechanisms that confer antibacterial drug resistance. Nature 406: $775-781$

Wang FQ, Smith DW, El-Din MG (2006) Aged raw landfill leachate: Membrane fractionation, $\mathrm{O}_{3}$ only and $\mathrm{O}_{3} / \mathrm{H}_{2} \mathrm{O}_{2}$ oxidation, and molecular size distribution 
analysis. Water Res 40: 463-474

Wang JQ, Chen JW, Qiao XL, Zhang YN, Uddin M, Guo ZY (2019) Disparate effects of DOM extracted from coastal seawaters and freshwaters on photodegradation of 2,4-Dihydroxybenzophenone. Water Res 151: 280-287

Wang XH, Lin YC (2012) Phototransformation of cephalosporin antibiotics in an aqueous environment results in higher toxicity. Environ Sci Technol 46: 1241712426

Wang ZW, Ma JX, Tang CY, Kimura K, Wang QY, Han XM (2014a) Membrane cleaning in membrane bioreactors: a review. J Membr Sci 468: 276-307

Wu J, Zhang H, He PJ, Shao LM (2011) Insight into the heavy metal binding potential of dissolved organic matter in MSW leachate using EEM quenching combined with PARAFAC analysis. Water Res 45: 1711-1719

Wu J, Zhang H, Yao QS, Shao LM, He PJ (2012) Toward understanding the role of individual fluorescent components in DOM-metal binding. J Hazard Mater 215216: $294-301$

Yu GH, Tang Z, Xu YC, Shen QR (2011) Multiple fluorescence labeling and two dimensional FTIR- ${ }^{13} \mathrm{C}$ NMR heterospectral correlation spectroscopy to characterize extracellular polymeric substances in biofilms produced during composting. Environ Sci Technol 45: 9224-9231

Zhao C, Wang CC, Li JQ, Wang P, Ou JQ, Cui JR (2017) Interactions between copper(II) and DOM in the urban stormwater runoff: modeling and characterizations. Environ Technol 39: 120-129 
642

643

644

645

646

647

Zhao XT, Hu ZZ, Yang X, Cai XW, Wang ZW, Xie XY (2019) Noncovalent interactions between fluoroquinolone antibiotics with dissolved organic matter: A ${ }^{1} \mathrm{H}$ NMR binding site study and multi-spectroscopic methods. Environ Pollut 248: 815-822

Zhou ZB, He X, Zhou MH, Meng FG (2017) Chemically induced alterations in the characteristics of fouling causing bio-macromolecules e Implications for the chemical cleaning of fouled membranes. Water Res 108: 115-123 


\section{Figures}

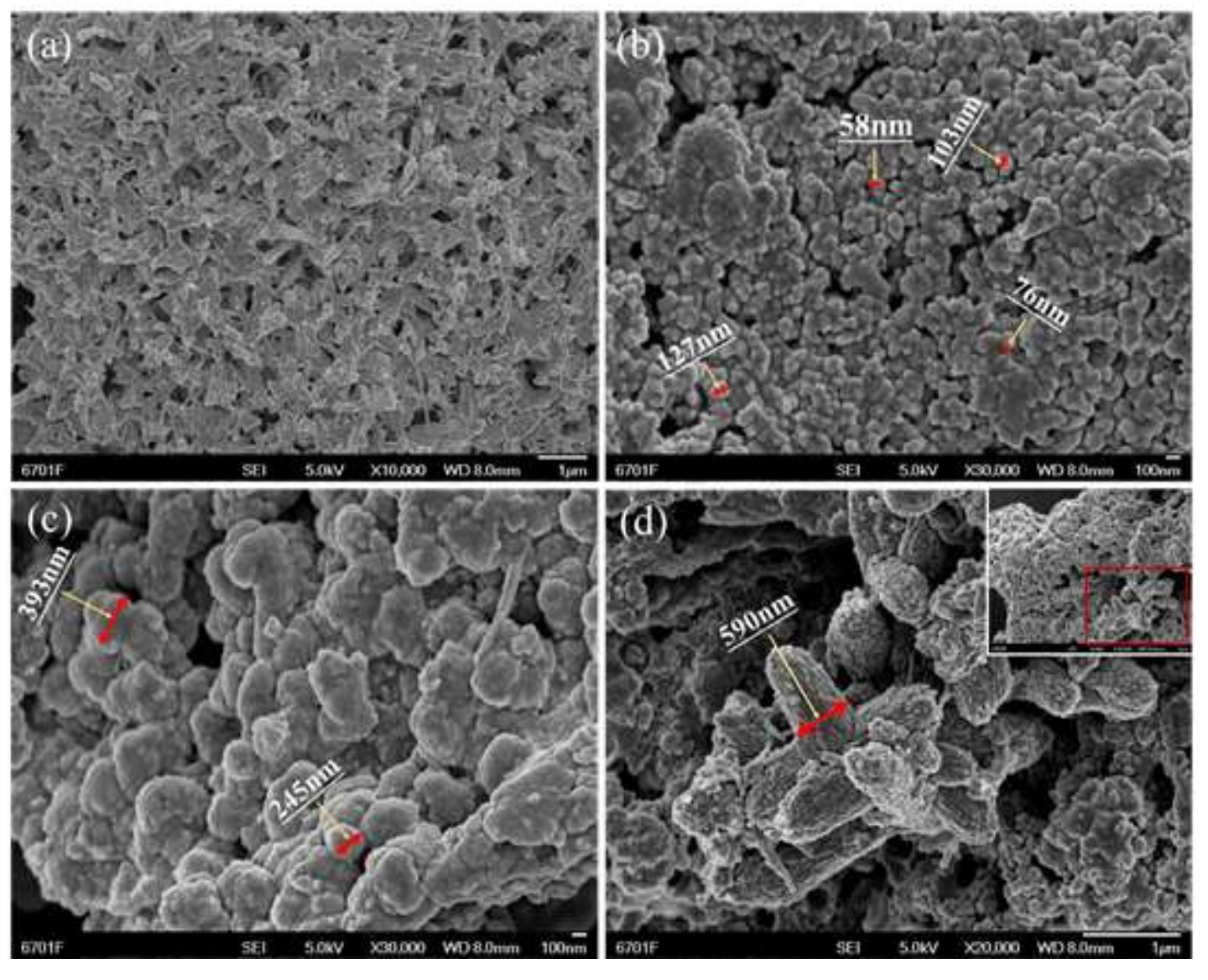

\section{Figure 1}

SEM images of SDOM: (a) the whole image at low magnification ( $\times 10,000)$; (b), (c) and (d) the different particle morphology at different sites. 

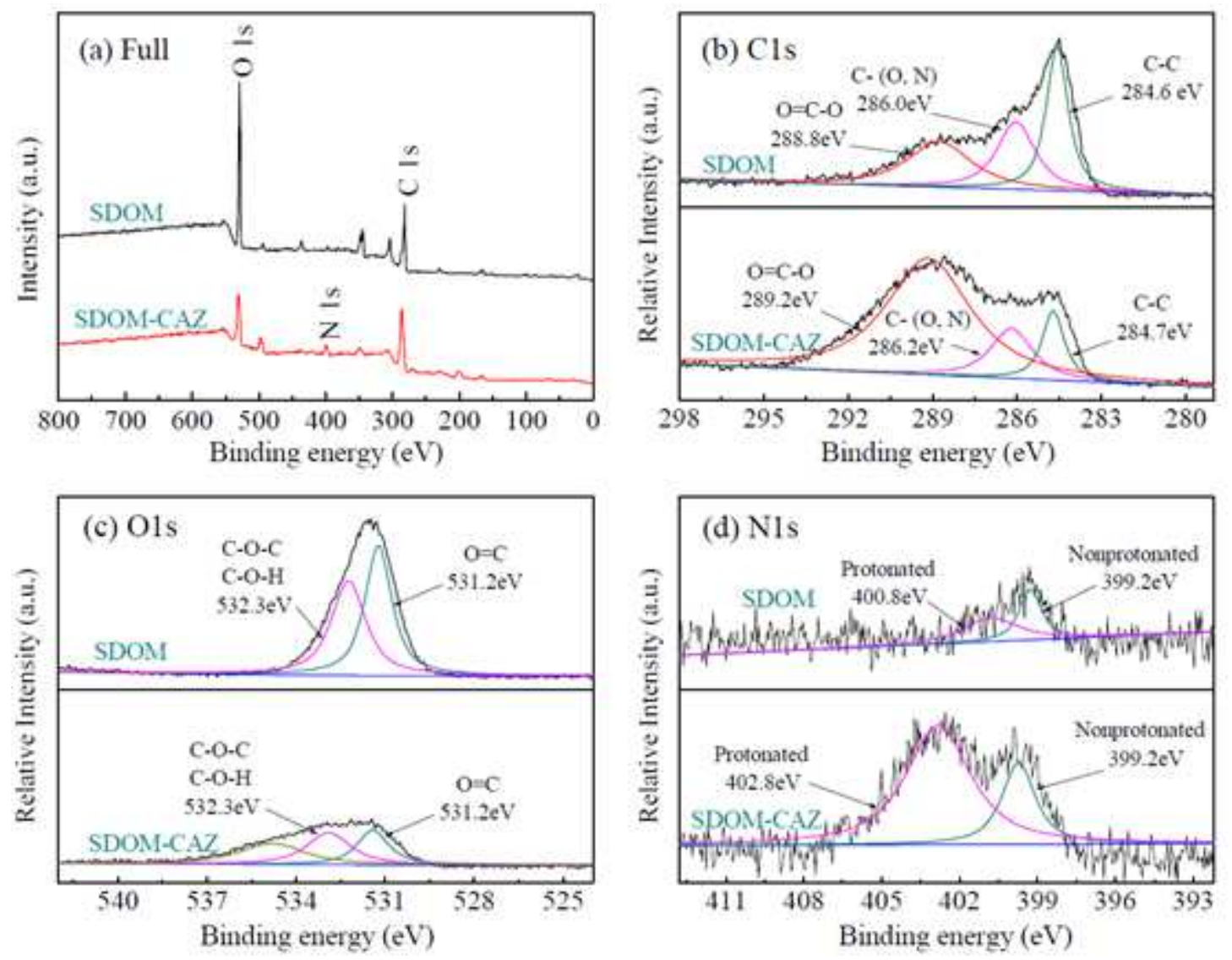

Figure 2

XPS spectra of SDOM and SDOM-CAZ system. (a) Full XPS spectra of SDOM and SDOM-CAZ; (b) C 1s, (c) $01 \mathrm{~s}$ and (d) N 1s, core-level spectra for SDOM and SDOM-CAZ, respectively. 


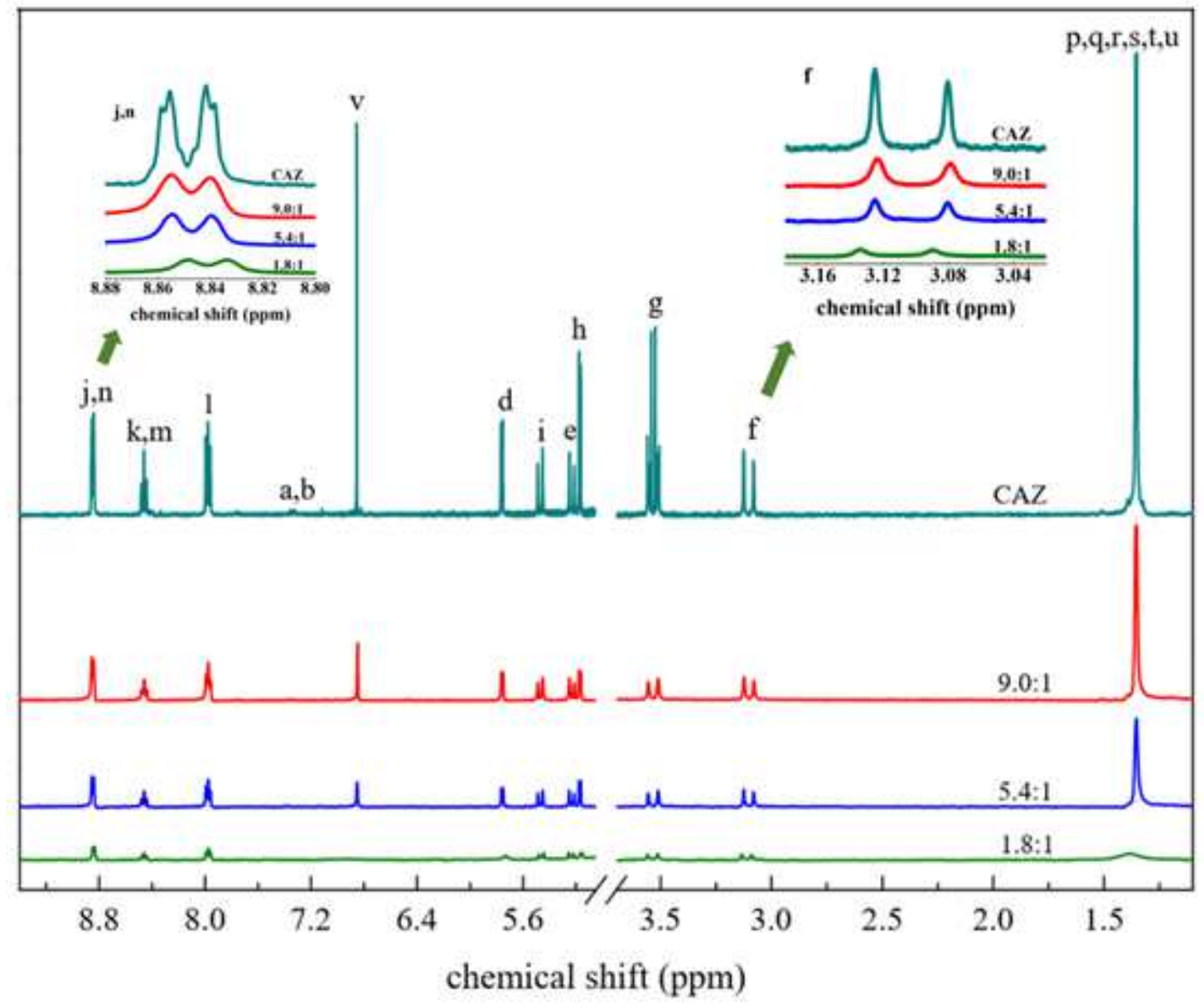

Figure 3

1H NMR spectra of CAZ at different mass concentration ratios of CAZ to SDOM (9.0:1, 5.4:1 and 1.8:1). Assignments were presented in the topmost spectra. 

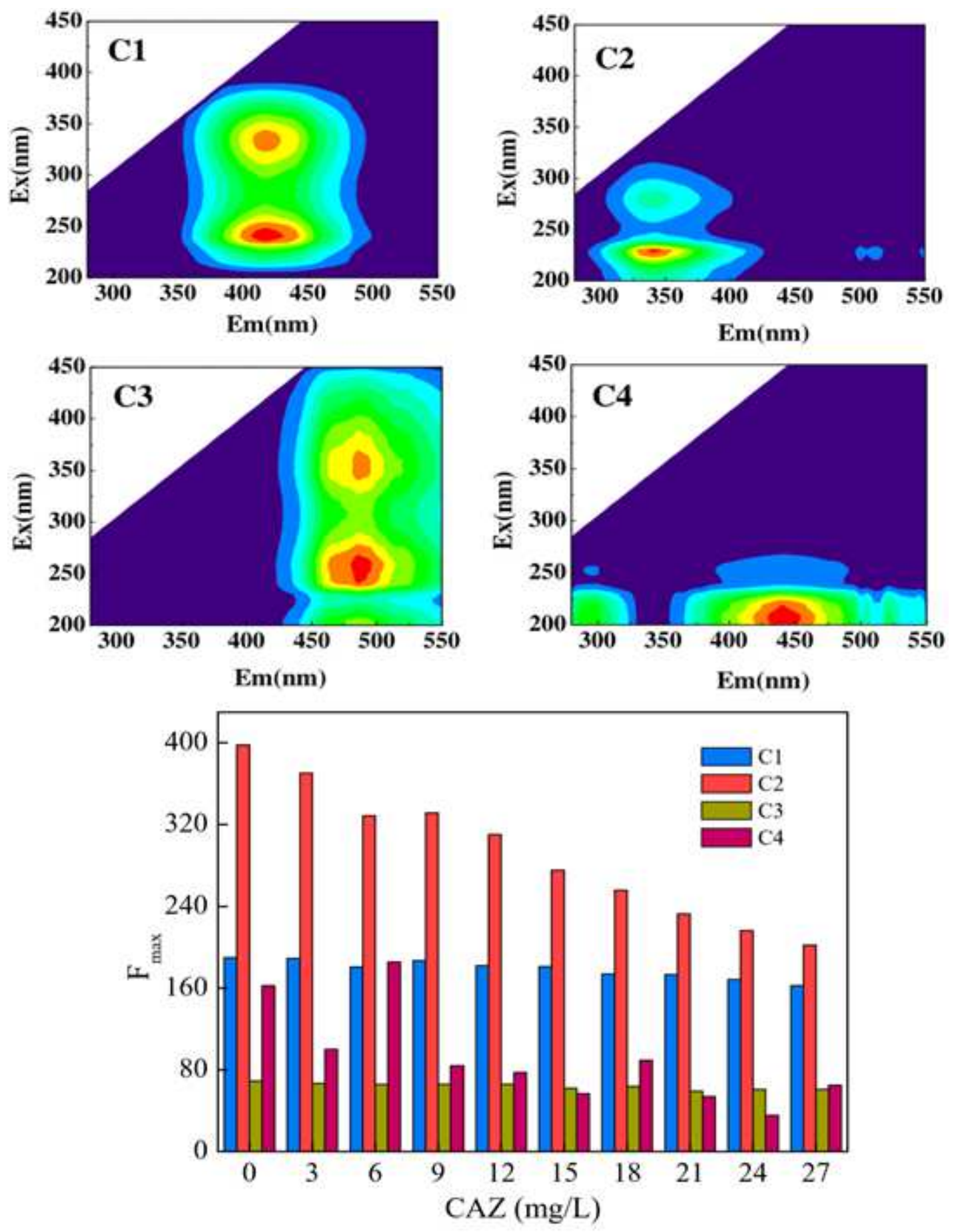

Figure 4

EEM fluorescence spectra of four PARAFAC-derived components $\mathrm{C} 1-\mathrm{C} 4$ and FMax value changes of SDOM with the increases of CAZ concentration (0, 3, 6 27 mg/L). 

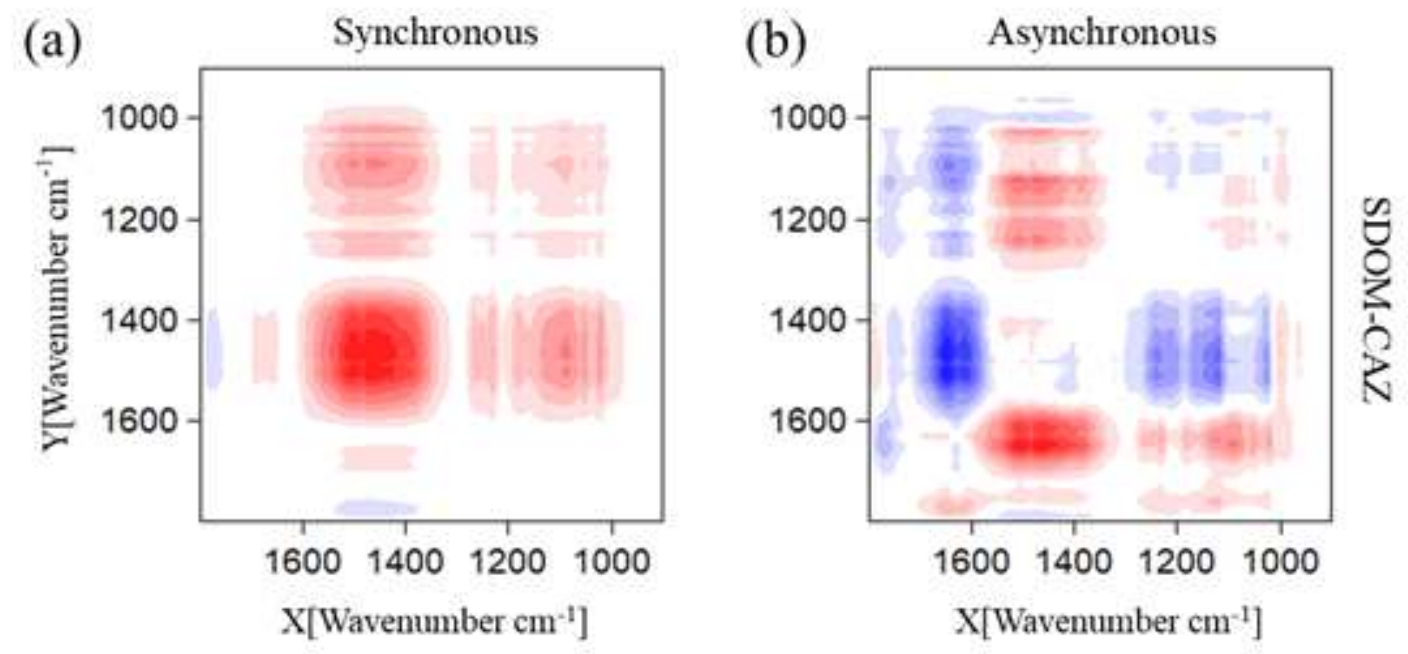

(c)

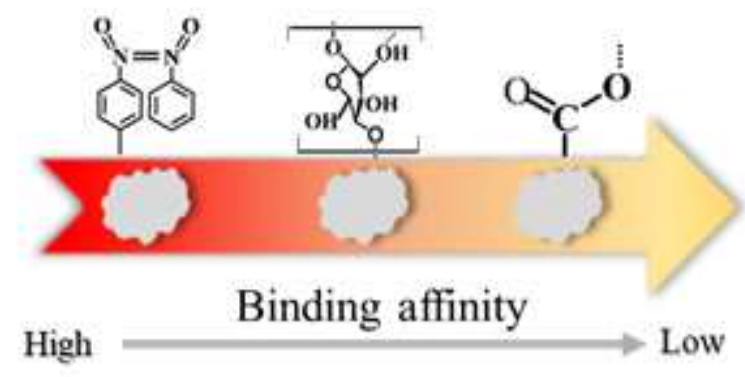

\section{Figure 5}

(a) and (b) 2D-COS maps obtained from the FTIR spectra of SDOM-CAZ. Red represents positive correlation and blue represents a negative correlation; an increase in the intensity of a particular color represents a stronger positive or negative correlation. (c) Binding affinities of SDOM with CAZ.

\section{Supplementary Files}

This is a list of supplementary files associated with this preprint. Click to download.

- Supplementarymaterial.doc 